\title{
Electrophysiological assessments of the motor pathway in diabetic patients with compressive cervical myelopathy
}

\author{
Kazuyoshi Nakanishi, MD, PhD, Nobuhiro Tanaka, MD, PhD, Naosuke Kamei, MD, PhD, \\ Takeshi Hiramatsu, MD, Satoshi Ujigo, MD, Norihiko Sumiyoshi, MD, Takanori Rikita, MD, \\ Atsushi Takazawa, MD, and Mitsuo Ochi, MD, PhD
}

Department of Orthopedic Surgery, Integrated Health Sciences, Institute of Biomedical \& Health Sciences, Hiroshima University, Hiroshima, Japan

OBJECT The occurrence of compressive cervical myelopathy (CCM) increases in adults over 50 years of age. In addition, diabetes mellitus (DM) is a frequent comorbidity for people of this age and may impact the severity of CCM. The authors assessed motor pathway function in diabetic patients with CCM to investigate the correlation between electrophysiological parameters and clinical symptoms.

METHODS Motor evoked potentials (MEPs) were measured from the abductor digiti minimi muscle (ADM) and the abductor hallucis muscle $(\mathrm{AH})$ following transcranial magnetic stimulation, as were $\mathrm{M}$ - and $\mathrm{F}$-waves following electrical stimulation of the ulnar and tibial nerves, in 22 patients with CCM and diabetes mellitus (DM) who had not experienced symptomatic diabetic neuropathy (CCM-DM group), in 92 patients with CCM alone (CCM group), and in 24 healthy adults (control group). The peripheral conduction time (PCT; measured from the ADM and AH) was calculated as follows: (Mwave latency + F-wave latency - 1)/2. The central motor conduction time (CMCT; measured from the ADM and AH) was calculated by subtracting the PCT from the onset latency of the MEPs. The Japanese Orthopaedic Association (JOA) score for cervical myelopathy was obtained before and 1 year after surgery as a clinical outcome measure.

RESULTS MEP, PCT, and CMCT parameters in the CCM-DM and CCM groups were significantly longer than those in the control group ( $p=0.000-0.007$ ). The PCTs in the CCM-DM group were significantly longer than those in the CCM group $(p=0.001-0.003$ ). No significant differences were detected in the MEP and CMCT parameters between the CCMDM and CCM groups $(p=0.080-1.000)$. The JOA score before surgery in the CCM-DM group was $10.7 \pm 2.0$ points and was significantly lower than that in the CCM group (12.2 \pm 2.5 points, $p=0.015)$. In the CCM-DM group, JOA scores before surgery correlated with MEP-AH $(r=-0.610, p=0.012)$ and PCT-AH $(r=-0.676, p=0.004)$ values, but not with CMCT values, while the JOA scores were related to both MEP and CMCT parameters in the CCM group. The JOA scores improved to $13.8 \pm 2.2$ points after surgery $(p=0.001)$ and correlated with MEP-AH $(r=-0.667, p=0.005)$ and PCT-AH ( $r=-0.611, p=0.012)$ in the CCM-DM group.

CONCLUSIONS The results suggest that MEP, PCT, and CMCT parameters each reveal abnormalities in the upper and lower motor neurons even in patients with DM. The results also show a prolonged PCT in CCM-DM patients, despite having no history of diabetic neuropathy. Corticospinal tract impairments are similar between CCM and CCM-DM patients, while the JOA score of the CCM-DM patients is lower than that in the CCM patients. The JOA score in CCM-DM patients may be influenced by additional impairments in peripheral nerves or other diabetic complications. These electrophysiological studies may be useful for screening motor pathway function for CCM in patients with DM.

http://thejns.org/doi/abs/10.3171/2015.3.SPINE141060

KEY WORDS transcranial magnetic stimulation; motor evoked potentials; central motor conduction time; peripheral conduction time; corticospinal tract; F-wave; diabetes mellitus; cervical myelopathy; cervical

ABBREVIATIONS ADM = abductor digiti minimi muscle; $\mathrm{AH}=$ abductor hallucis muscle; $\mathrm{BMI}=$ body mass index; $\mathrm{CCM}=$ compressive cervical myelopathy; $\mathrm{CMAP}=$ compound muscle action potential; $\mathrm{CMCT}=$ central motor conduction time; $\mathrm{CSM}=$ cervical spondylotic myelopathy; $\mathrm{DM}=$ diabetes mellitus; $\mathrm{JOA}=\mathrm{Japanese}$ Orthopaedic Association; MEP = motor evoked potential; OPLL = ossification of the posterior longitudinal ligament; PCT = peripheral conduction time; TMS = transcranial magnetic stimulation. SUBMITTED October 22, 2014. ACCEPTED March 26, 2015.

INCLUDE WHEN CITING Published online September 4, 2015; DOI: 10.3171/2015.3.SPINE141060. 


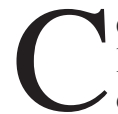
OMPRESSIVE cervical myelopathy (CCM) is a prevalent and increasingly observed neurological disorder in adults over 50 years of age. ${ }^{11,21}$ Distinctive symptoms of CCM are numbness in the extremities, clumsiness in the hands, spastic gait disturbance, and bladder and bowel dysfunction. Diabetes mellitus (DM) is a frequent comorbidity and can cause numbness and weakness in the extremities due to peripheral neuropathy. Therefore, DM may impact the severity of CCM.

The measurement of motor evoked potentials (MEPs) following transcranial magnetic stimulation (TMS) is a noninvasive method to evaluate the electrophysiological function of the corticospinal tract. ${ }^{13,26}$ Central motor conduction time (CMCT) can be used to evaluate corticospinal function in cervical myelopathy, and prolonged CMCT has been reported in patients with CCM. ${ }^{6,15,33,40}$ In addition, F-wave studies have been reported to be able to detect diabetic neuropathy. ${ }^{1,20,34}$ Motor conduction latencies are increased in patients with diabetic neuropathy. ${ }^{18} \mathrm{How}-$ ever, few reports have examined the electrophysiological assessment of diabetic patients with CCM. Motor pathway conductivity in CCM patients with DM who have not been diagnosed with diabetic polyneuropathy has not been examined, and the correlation between the electrophysiological parameters and clinical symptoms is unclear.

The aim of this study was to assess the function of motor pathways in diabetic patients with CCM and to investigate the correlation between electrophysiological parameters and clinical symptoms.

\section{Methods \\ Study Population}

Among 142 patients treated in the Department of Orthopedic Surgery at Hiroshima University between 2011 and 2013, 22 patients (10 women and 12 men) had CCM and DM (CCM-DM group) and 92 patients (26 women and 66 men) had CCM alone (CCM group). All patients in the CCM-DM and CCM groups presented with symptoms of myelopathy, such as numbness or sensory disturbance in the upper and/or lower limbs, clumsiness in the hand, spasticity in the lower limb, and/or bladder and bowel dysfunction. Myelopathy in each patient was confirmed by physical examination, and cord compression was present between C2-3 and C5-6 disc levels on MRI and myelography findings. The remaining 28 patients presented with other brain, thoracic spinal cord, cauda equina, or entrapment peripheral nerve disorders and were excluded from the study.

All patients in the CCM-DM group were diagnosed with Type II DM, according to the classification and diagnostic criteria for DM presented by the Committee of the Japan Diabetes Society on the Diagnostic Criteria of Diabetes Mellitus, ${ }^{22}$ and were treated for more than 1 year after receiving their diagnosis. The mean treatment period for DM was $7.4 \pm 5.7$ years (range $1-19$ years). Of these 22 patients, 3 were treated with insulin and 19 were treated with hypoglycemic medication. Patients with Type I DM were excluded from the study. Patients diagnosed with symptomatic diabetic neuropathy before the onset of CCM were also excluded. In the CCM-DM group, 4 patients had a history of ischemic heart disease, 2 had diabetic retinopathy, and 4 had a mild degree of nephropathy before surgery. The CCM group excluded patients with fasting blood glucose levels of $126 \mathrm{mg} / \mathrm{dl}$ or more, or with HbA1c levels of $6.5 \%$ or more on blood screening before surgery. The mean age, height, and body mass index (BMI) of the CCM-DM group were $74.2 \pm 11.4$ years (range 42-94 years), $157.7 \pm 12.4 \mathrm{~cm}$ (range 135.0-181.0 $\mathrm{cm}$ ), and $23.5 \pm 3.3 \mathrm{~kg} / \mathrm{m}^{2}$ (17.6-30.8), respectively (Table $1)$. The mean age, height, and BMI of the CCM group were $68.9 \pm 12.1$ years (range $30-92$ years), $159.1 \pm 9.7 \mathrm{~cm}$ (range 140.0-179.0 cm), and $23.4 \pm 4.0 \mathrm{~kg} / \mathrm{m}^{2}(12.9-35.2$ $\mathrm{kg} / \mathrm{m}^{2}$ ), respectively.

We also examined 24 healthy adults (14 women and 10 men) as the control group. The mean age of adults in the control group was $67.5 \pm 11.9$ years (range $45-86$ years). The mean height and BMI of the controls were $155.9 \pm 8.3$ $\mathrm{cm}$ (range $143.5-170.0 \mathrm{~cm}$ ) and $23.3 \pm 3.5 \mathrm{~kg} / \mathrm{m}^{2}(18.2-$ $32.5 \mathrm{~kg} / \mathrm{m}^{2}$ ), respectively. Adults in the control group showed no sensory disturbance, weakness, or spastic gait disturbance in their limbs. There were no significant differences in age, height, or BMI among the 3 groups. All patients provided written informed consent after full explanation of the treatment. All participants and/or their families were informed that their data would be submitted for publication. This study received approval from the institutional review board of Hiroshima University.

\section{Clinical Outcomes}

The presence of CCM in the CCM-DM group was due to either cervical spondylosis (20 patients) or ossification of the posterior longitudinal ligament (OPLL; 2 patients). In the CCM group, the CCM was due to cervical spondylosis (79 patients), OPLL (8 patients), or cervical disc herniation (5 patients). Compression was detected in the $\mathrm{C} 2-$ 3, C3-4, C4-5, and/or C5-6 levels by MRI. All patients underwent laminoplasty ${ }^{39}$ and some exhibited neurological improvement. The Japanese Orthopaedic Association (JOA) score for cervical myelopathy ${ }^{42}$ (highest score is 17 points) was obtained as a clinical outcome before surgery and at 1 year after surgery by independent orthopedic surgeons (Table 1).

\section{Electrophysiological Assessments}

CMCT was determined as described previously ${ }^{29,30,32}$ and was measured for all patients before surgery. Surface recording electrodes were placed bilaterally on the abductor digiti minimi muscle (ADM) and abductor hallucis muscle $(\mathrm{AH})$ using the standard belly-tendon method. TMS was delivered using a round coil with a 14-cm outer diameter (The Magstim Company, Ltd.), whose center was held over the vertex of the cranium while MEP recordings were made from the ADM. TMS was applied during a slight voluntary contraction. The recording sensitivity was set at a vertical gain of $0.2 \mathrm{mV} / \mathrm{D}$ and a horizontal sweep of $5 \mathrm{msec} / \mathrm{D}$ for $\mathrm{ADM}$ recordings. The recording sensitivity was set at a vertical gain of $0.1 \mathrm{mV} / \mathrm{D}$ and a horizontal sweep of $10 \mathrm{msec} / \mathrm{D}$ for $\mathrm{AH}$ recordings. A clockwise current in the coil, as viewed from above, was delivered to stimulate the left hemisphere, and a counterclockwise current was used to stimulate the right hemisphere. The mag- 
TABLE 1. Age, height, BMI, and JOA score before and after surgery in 138 study participants

\begin{tabular}{|c|c|c|c|c|c|c|}
\hline Group & Age (yrs) & Height (cm) & BMI $\left(\mathrm{kg} / \mathrm{m}^{2}\right)$ & $\begin{array}{l}\text { Duration Btwn Onset of CCM } \\
\qquad \& \mathrm{ES} \text { (mos) }\end{array}$ & JOA Score Before Op & JOA Score After Op \\
\hline \multicolumn{7}{|l|}{ CCM-DM } \\
\hline Mean & 74.2 & 157.7 & 23.5 & 8.3 & 10.7 & 13.8 \\
\hline SD & 11.4 & 12.4 & 3.3 & 7.7 & 2.0 & 2.2 \\
\hline Min & 42 & 135.0 & 17.6 & 1 & 7 & 9 \\
\hline Max & 94 & 181.0 & 30.8 & 24 & 14.5 & 16.5 \\
\hline \multicolumn{7}{|l|}{$\mathrm{CCM}$} \\
\hline Mean & 68.9 & 159.1 & 23.4 & 11.3 & 12.2 & 14.5 \\
\hline SD & 12.1 & 9.7 & 4.0 & 15.5 & 2.5 & 2.1 \\
\hline Min & 30 & 140.0 & 12.9 & 1 & 5 & 7 \\
\hline Max & 92 & 179.0 & 35.2 & 60 & 16 & 17 \\
\hline \multicolumn{7}{|l|}{ Control } \\
\hline Mean & 67.5 & 155.9 & 23.3 & & & \\
\hline SD & 11.9 & 8.3 & 3.5 & & & \\
\hline Min & 45 & 143.5 & 18.2 & & & \\
\hline Max & 86 & 170.0 & 32.5 & & & \\
\hline
\end{tabular}

ES = electrophysiological study.

netic stimulus intensity was set at $20 \%$ above the threshold for the MEPs. The coil was then shifted anteriorly when the MEP recordings were made from the AH muscle. The MEPs were recorded more than 10 times; 4 reproducible responses were superimposed, and their latencies were measured. For most trials, a stimulus intensity of $80 \%$ was adequate to elicit consistent MEPs of similar morphology.

$\mathrm{M}$-waves and F-waves were recorded following continuous current stimulation at supramaximal intensity (0.2msec square wave pulses) of the ulnar and tibial nerves at the wrist and ankle, respectively. None of the patients showed markedly diminished compound muscle action potential (CMAP) amplitudes in either the ADM or the AH. Thirty-two serial responses were obtained, and the shortest F-wave latency was measured. All muscle responses were recorded using a commercially available system (Viking IV, Nicolet Biomedical, Inc.) after they traversed a bandpass filter of $0.5-2000 \mathrm{~Hz}$. An epoch of 100 msec after stimulation was digitized at a $5-\mathrm{kHz}$ sampling rate. The peripheral conduction time (PCT), excluding the turnaround time at the spinal motor neuron $(1 \mathrm{msec})$, was calculated from the latencies of the CMAPs and F-waves as follows: (M-wave latency $+\mathrm{F}$-wave latency -1$) / 2 .{ }^{17}$ The conduction time from the motor cortex to the spinal motor neurons (i.e., the CMCT) was calculated by subtracting the PCT from the onset latency of the MEPs (Fig. 1). These measurements were performed by an examiner, who was blinded to the patient's history, clinical features, and MRI results, in an electrically shielded room with the air temperature controlled at $25^{\circ}-27^{\circ} \mathrm{C}$. The mean disease duration between the onset of CCM and the electrophysiological study was $8.3 \pm 7.7$ months (range $1-24$ months) in the CCM-DM group and $11.3 \pm 15.5$ months (range $1-60$ months) in the CCM group. There were no significant differences in the mean disease duration between the CCM$\mathrm{DM}$ and CCM groups. The electrophysiological data are presented as the mean \pm standard deviation (range).

\section{Statistical Analysis}

Statistical analyses were performed using PASW Statistics 18 (SPSS, Inc.). The MEP, PCT, and CMCT data were analyzed using averages of right and left values. Data were compared among the 3 groups using the Scheffé test with ANOVA, and a $\mathrm{p}$ value of $<0.05$ was considered to be statistically significant. Correlations among the JOA score, age, and CMCT values were estimated using the Pearson correlation coefficient (r). It has been reported that height and age are correlated significantly with F-wave latency in the upper and lower limbs. ${ }^{7,36,43}$ In healthy subjects, significant correlations between CMCT in the lower limbs and height also have been reported. ${ }^{3,4,8,9,12,41}$ Age also correlates with JOA score in patients with CCM. ${ }^{10,24,27,28}$ Therefore, the partial correlation coefficient ( $\mathrm{r}^{\prime}$ ) was analyzed after adjusting for age and height. A correlation was accepted as significant when $\mathrm{p}<0.05$ and $\mid r$ or $\mathrm{r}^{\prime} \mid>0.2$.

The parameters were considered abnormal if no response could be recorded or if the response value in the right and/or left side exceeded the upper limit of the normal range, defined as the mean $\pm 2.0 \mathrm{SD}$. Comparisons of the frequencies of different nominally scaled variables were performed between the CCM-DM and CCM groups using the chi-square test. The results were considered significant if $\mathrm{p}<0.05$. The electrophysiological data are presented as the mean \pm standard deviation (range).

\section{Results \\ The MEP Latency, PCT, and CMCT Values}

The MEP latency, PCT, and CMCT values are shown in Table 2. MEP latencies recorded in the ADM and AH muscles are defined as MEP-ADM and MEP-AH, respectively. PCT and CMCT detected from the ADM and AH muscles are defined as PCT-ADM and PCT-AH and CMCT-ADM and CMCT-AH, respectively. The MEP 
could not be recorded from the left $\mathrm{AH}$ in 1 patient in the CCM-DM group. The MEP could not be recorded from the right and left ADM and both AHs in 1 patient, from the right $\mathrm{AH}$ in 1 patient, and from the left $\mathrm{AH}$ in 1 patient in the CCM group. Among the 3 groups, all of the MEP latency, PCT, and CMCT parameters in the ADM or $\mathrm{AH}$ of the CCM-DM and CCM groups were significantly longer than those of the control group $(\mathrm{p}=0.000-0.007)$. The PCTs in the CCM-DM group were significantly longer than those in the CCM group, but no significant differences were observed in the MEP or CMCT parameters between the CCM-DM and CCM groups ( $\mathrm{p}=0.080-1.000)$.

\section{Clinical Outcomes}

The mean JOA score before surgery in the CCM-DM was $10.7 \pm 2.0$ points (range 7-14.5 points) and was significantly lower than that in the CCM group $(12.2 \pm 2.5$ points, range 5-16 points; Mann-Whitney U-test, $\mathrm{p}=$ 0.015 ; Table 1). The JOA score was improved significantly at 1 year after surgery to $13.8 \pm 2.2$ points (range $9-16.5$ points) in the CCM-DM group (Wilcoxon signed-rank test, $\mathrm{p}=0.001$ ) and to $14.5 \pm 2.1$ points (range 7-17 points) in the CCM group $(\mathrm{p}=0.000)$.

\section{Correlations Between the JOA Scores and Electrophysiological Parameters}

The correlations between the JOA score or CMCT values in the CCM-DM and CCM groups are shown in Tables 3 and 4. In the CCM-DM group, the JOA score before surgery was negatively correlated with MEP-AH $(r=$ $-0.610, \mathrm{p}=0.012)$ and PCT-AH $(\mathrm{r}=-0.676, \mathrm{p}=0.004)$. The JOA score before surgery showed a negative correlation with MEP and CMCT parameters in the CCM group $(\mathrm{r}=-0.446$ to $-0.360, \mathrm{p}=0.000-0.003)$. The JOA score after surgery correlated significantly with MEP-AH ( $\mathrm{r}=$ $-0.667, \mathrm{p}=0.005)$ and PCT-AH $(\mathrm{r}=-0.611, \mathrm{p}=0.012)$ in the CCM-DM group, while there was significant correlation with MEP-ADM $(r=-0.267, \mathrm{p}=0.032)$ and CMCT$\operatorname{ADM}(r=-0.254, p=0.041)$ in the CCM group.

The JOA score correlated significantly with age in the CCM-DM group both before $(\mathrm{r}=-0.686, \mathrm{p}=0.003)$ and after surgery $(r=-0.695, p=0.003)$. Similarly, the JOA score correlated with age in the CCM group both before $(\mathrm{r}=-0.391, \mathrm{p}=0.001)$ and after surgery $(\mathrm{r}=-0.382, \mathrm{p}$ $=0.002)$. The Pearson correlation coefficients (r) between height and JOA score in the CCM-DM group were 0.293 $(\mathrm{p}=0.270)$ before surgery and $0.246(\mathrm{p}=0.358)$ after surgery. The Pearson correlation coefficients (r) between height and JOA score in the CCM group were 0.188 ( $\mathrm{p}=$ $0.134)$ before surgery and $0.169(\mathrm{p}=0.178)$ after surgery. Even when calculating the partial correlation coefficient (r') after adjustment for age and height, the JOA score was negatively correlated with MEP-AH and PCT-AH before and after surgery in the CCM-DM group ( $\mathrm{r}=-0.829$ to $-0.603, \mathrm{p}=0.000-0.023$ ) and with MEP and CMCT before surgery in the CCM group $(r=-0.450$ to $-0.385, p=$ $0.000-0.002)$.

\section{Rate of Electrophysiological Abnormalities}

The rates of electrophysiological abnormalities in the

\section{MEP waveforms following TMS}

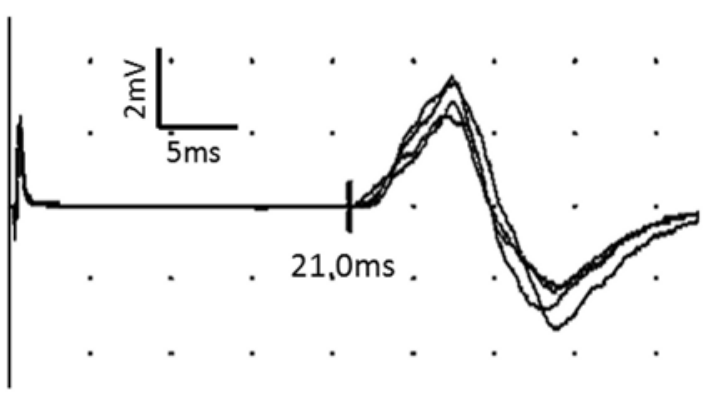

M- and F-waves following ulnar nerve stimulation

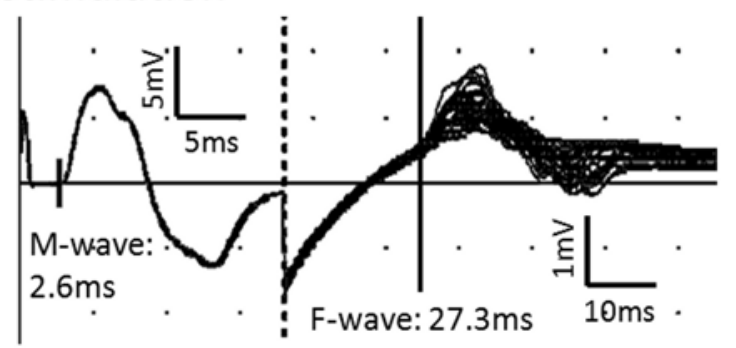

$$
\begin{aligned}
& \text { MEP latency }=21.0 \mathrm{~ms} \\
& \begin{aligned}
\mathrm{PCT} & =(\mathrm{M} \text {-wave latency }+\mathrm{F} \text {-wave latency }-1 \mathrm{~ms}) / 2 \\
& =(2.6 \mathrm{~ms}+27.3 \mathrm{~ms}-1 \mathrm{~ms}) / 2=14.45 \mathrm{~ms} \\
\mathrm{CMCT} & =\mathrm{MEP} \text { latency }-\mathrm{PCT} \\
& =21.0 \mathrm{~ms}-14.45 \mathrm{~ms}=6.55 \mathrm{~ms}
\end{aligned}
\end{aligned}
$$

FIG. 1. Example calculations for CMCT. Upper: Superimposed MEP waveforms detected from the ADM following TMS show that the MEP latency is $21.0 \mathrm{msec}(\mathrm{ms})$. Lower: Superimposed M- and F-waves detected from the ADM following ulnar nerve electrical stimulation show that M-wave latency is $2.6 \mathrm{~ms}$ and $\mathrm{F}$-wave latency is $27.3 \mathrm{~ms}$. The formulas indicate that the PCT is $14.45 \mathrm{~ms}$ and the CMCT is $6.55 \mathrm{~ms}$.

CCM-DM and CCM groups are shown in Table 5. PCT$\mathrm{ADM}$ and PCT-AH abnormalities were detected in 16 patients (73\%) and 13 patients (59\%) in the CCM-DM group, respectively. In total, PCT abnormalities were observed in the ADM and/or AH muscles in 17 (77\%) CCM-DM patients. In contrast, PCT-ADM and PCT-AH abnormalities were detected in 38 patients $(41 \%)$ and 23 patients $(25 \%)$ in the CCM group, respectively. The rate of PCT-AH and MEP-AH abnormalities in the CCM-DM group was significantly higher than that in the CCM group $(\mathrm{p}=0.004$ 0.029). CMCT-ADM and CMCT-AH abnormalities were detected in 12 patients (54\%) and 19 patients (86\%) in the CCM-DM group, respectively. In total, CMCT abnormalities were observed in the ADM and/or AH muscles in 20 (91\%) CCM-DM patients. There were no significant differences in the rate of CMCT abnormalities between the CCM-DM and CCM groups ( $\mathrm{p}=0.074-0.815)$.

\section{Discussion}

Our results demonstrate a prolonged PCT in patients in the CCM-DM group as compared with that in patients in 
TABLE 2. The MEP latency, PCT, and CMCT values of subjects in the CCM-DM, CCM, and control groups*

\begin{tabular}{|c|c|c|c|c|c|c|}
\hline Group & MEP-ADM & PCT-ADM & CMCT-ADM & MEP-AH & PCT-AH & CMCT-AH \\
\hline \multicolumn{7}{|l|}{ CCM-DM } \\
\hline No. & 22 & 22 & 22 & 22 & 22 & 22 \\
\hline Mean & 25.8 & 15.4 & 10.4 & 46.2 & 28.0 & 18.2 \\
\hline $\mathrm{SD}$ & 4.9 & 1.5 & 4.0 & 5.4 & 3.6 & 3.3 \\
\hline Min & 19.6 & 12.6 & 6.1 & 39.1 & 23.4 & 13.6 \\
\hline Max & 35.8 & 18.2 & 19.8 & 58.0 & 39.2 & 27.1 \\
\hline p vs CCM & 0.498 & $0.003 \dagger$ & 1.000 & 0.080 & $0.001 \dagger$ & 0.971 \\
\hline p vs control & $0.000 \ddagger$ & $0.000 \ddagger$ & $0.000 \ddagger$ & $0.000 \ddagger$ & $0.003 \dagger$ & $0.000 \ddagger$ \\
\hline \multicolumn{7}{|l|}{$\mathrm{CCM}$} \\
\hline No. & 91 & 92 & 91 & 91 & 92 & 91 \\
\hline Mean & 24.8 & 14.4 & 10.4 & 43.7 & 25.8 & 18.0 \\
\hline SD & 3.5 & 1.1 & 3.3 & 4.8 & 2.1 & 4.1 \\
\hline Min & 19.0 & 11.6 & 5.6 & 37.0 & 20.8 & 11.7 \\
\hline Max & 36.6 & 16.8 & 20.3 & 57.3 & 31.1 & 29.8 \\
\hline p vs control & $0.000 \ddagger$ & $0.000 \ddagger$ & $0.007 \dagger$ & $0.000 \ddagger$ & $0.000 \ddagger$ & $0.002 \dagger$ \\
\hline \multicolumn{7}{|l|}{ Control } \\
\hline No. & 24 & 24 & 24 & 24 & 24 & 24 \\
\hline Mean & 20.4 & 13.0 & 7.4 & 38.2 & 23.9 & 14.3 \\
\hline $\mathrm{SD}$ & 1.4 & 1.0 & 0.8 & 2.2 & 1.8 & 1.0 \\
\hline Min & 17.9 & 11.1 & 6.1 & 34.1 & 19.5 & 12.8 \\
\hline Max & 23.5 & 14.9 & 9.5 & 43.4 & 27.9 & 16.5 \\
\hline
\end{tabular}

* The MEP could not be recorded from the left AH in 1 patient in the CCM-DM group. The MEP could not be recorded from the right and left $\mathrm{ADM}$ and both $\mathrm{AH}$ in 1 patient, from the right $\mathrm{AH}$ in 1 patient, and from the left $\mathrm{AH}$ in 1 patient in the CCM group.

$\dagger p<0.01$.

$\ddagger p<0.001$.

the CCM group, even though the diabetic patients had not experienced a symptomatic diabetic neuropathy before the onset of CCM. CMCT was prolonged in patients in both the CCM-DM and CCM groups as compared with that in the control group; however, no significant differences in CMCT were observed between the CCM-DM and CCM groups. However, the JOA score of the CCM-DM group was significantly lower than that of the CCM group. In the CCM-DM group, the JOA score correlated with the MEP$\mathrm{AH}$ and PCT-AH, but not with other electrophysiological parameters. There were significant correlations between the JOA score and both the MEP and CMCT values in the CCM group.

In our case series, PCT parameters calculated from Fwave and $\mathrm{M}$-wave latencies were significantly longer in the CCM-DM group than those in the CCM or control group. F-wave latencies elicited by distal stimulation represent the motor conduction time to and from the spinal cord along the entire motor nerve axon. ${ }^{5,16,19,35}$ Abnormalities in F-wave latencies have been reported in patients with diabetic neuropathy, as well as in subclinical asymptomatic patients. Pan et al. examined F-wave latency in the me-

TABLE 3. Correlations between JOA score before surgery and MEP, PCT, or CMCT values

\begin{tabular}{cccccrr}
\hline Group & MEP-ADM & PCT-ADM & CMCT-ADM & MEP-AH & PCT-AH & CMCT-AH \\
\hline CCM-DM & & & & & & -0.183 \\
\hline$r$ & -0.343 & -0.343 & -0.184 & $-0.610 \dagger$ & $-0.676 \dagger$ & 0.497 \\
\hline$p$ for $r$ & 0.267 & 0.193 & 0.494 & 0.012 & 0.004 & -0.262 \\
\hline$r^{\prime}$ & -0.357 & -0.396 & -0.143 & $-0.603 \dagger$ & $-0.829 \dagger$ & 0.365 \\
\hline$p$ for r' & 0.171 & 0.161 & 0.626 & 0.023 & 0.000 & $-0.360^{*}$ \\
\hline CCM & & & & & -0.193 & 0.003 \\
\hline$r$ & $-0.446 \dagger$ & -0.228 & $-0.400^{*}$ & $-0.394^{*}$ & 0.123 & $-0.385^{*}$ \\
\hline$p$ for $r$ & 0.000 & 0.068 & 0.001 & 0.001 & -0.155 & 0.002 \\
\hline$r^{\prime}$ & $-0.450 \dagger$ & -0.236 & $-0.410 \dagger$ & $-0.398^{*}$ & 0.224 & 0.001 \\
\hline$p$ for r' & 0.000 & 0.063 & 0.001 & & & 0.001 \\
\hline
\end{tabular}

* $0.2<\mid$ or $r^{\prime} \mid \leq 0.4$.

† $0.4<\mid r$ or r' $\mid$. 
TABLE 4. Correlations between JOA score 1 year after surgery and MEP, PCT, or CMCT values

\begin{tabular}{|c|c|c|c|c|c|c|}
\hline Group & MEP-ADM & PCT-ADM & CMCT-ADM & MEP-AH & РCT-AH & СMCT-АН \\
\hline \multicolumn{7}{|l|}{ CCM-DM } \\
\hline$r$ & -0.312 & -0.334 & -0.248 & $-0.667 \dagger$ & $-0.611 \dagger$ & -0.353 \\
\hline$p$ for $r$ & 0.240 & 0.206 & 0.354 & 0.005 & 0.012 & 0.180 \\
\hline$r^{\prime}$ & -0.295 & -0.359 & -0.193 & $-0.644 \dagger$ & $-0.696 \dagger$ & -0.262 \\
\hline$p$ for $r^{\prime}$ & 0.306 & 0.207 & 0.508 & 0.013 & 0.006 & 0.365 \\
\hline \multicolumn{7}{|l|}{$\mathrm{CCM}$} \\
\hline$r$ & $-0.267^{*}$ & -0.092 & $-0.254^{*}$ & -0.158 & -0.127 & -0.117 \\
\hline$p$ for $r$ & 0.032 & 0.466 & 0.041 & 0.209 & 0.314 & 0.354 \\
\hline$r^{\prime}$ & $-0.249^{*}$ & -0.047 & $-0.251^{*}$ & -0.126 & -0.054 & -0.120 \\
\hline$p$ for r' & 0.049 & 0.717 & 0.047 & 0.326 & 0.672 & 0.350 \\
\hline
\end{tabular}

dian, ulnar, tibial, peroneal, and sural nerves in symptomatic and asymptomatic patients with diabetic neuropathy and reported that abnormalities were observed in $84 \%$ of symptomatic patients and $36 \%$ of asymptomatic patients. ${ }^{34}$ While our CCM-DM group did not include patients who had experienced symptomatic diabetic neuropathy, the PCT values were longer in that group than in the CCM group, and abnormalities were detected in $73 \%$ of patients in the PCT-ADM and $59 \%$ of patients in the PCT-AH. Of the 22 patients in the CCM-DM group, despite not being diagnosed with diabetic polyneuropathy before the onset of CCM, 17 patients (77\%) presented abnormal PCT in the upper and/or lower limbs, suggesting that these patients had asymptomatic diabetic neuropathy or developed deterioration in the lower motor neuron after the onset of CCM.

CMCT is calculated by subtracting PCT from the MEP latency and can be used to evaluate corticospinal function in cervical myelopathy. Corticospinal conduction block is thought to cause CMCT prolongation, ${ }^{15,29,30}$ and CMCT is more prolonged in patients with more severe cervical spinal cord compression, according to MRI analysis. ${ }^{23}$ However, few reports have conducted electrophysiological assessment of diabetic patients with CCM. Chistyakov et al. examined MEPs and somatosensory evoked potentials in 9 patients with combined CCM and diabetic neuropathy. ${ }^{2}$ They identified CMCT abnormalities in 6 (66.7\%) of these patients and peripheral latencies calculated from F-wave and M-wave latencies in $8(88.9 \%)$ patients. In the present study, the CMCT parameters were prolonged significantly in $12(54 \%)$ patients in the CMCT-ADM and in $19(86 \%)$ patients in the CMCT-AH. Together, CMCT abnormalities were observed in 20 (91\%) patients, and PCT abnormalities were observed in $17(77 \%)$ patients in the upper and/ or lower limbs. These results suggest that electrophysiological measurements can detect abnormalities in upper and lower motor neurons, even in patients with DM. These results are similar to the prolonged CMCT observed in patients with coexisting entrapment neuropathy and CCM, as reported previously. ${ }^{14}$

Machino et al. compared the JOA score between diabetic patients with cervical spondylotic myelopathy (CSM) and nondiabetic patients with CSM and concluded that the pre- and postoperative JOA scores and recovery rate were lower in the diabetic group than in the nondiabetic group, while the achieved JOA scores were not significantly different between these 2 groups. ${ }^{25}$ In the present study, the JOA score before surgery in the CCM-DM group was significantly lower than that in the CCM group, while there were no significant differences in the CMCT parameters (i.e., corticospinal tract impairments) between the CCMDM and the CCM groups, suggesting that the JOA score in the diabetic patients may be influenced by additional impairments in peripheral nerves or other diabetic complications.

TABLE 5. Rate of electrophysiological abnormalities in the CCM-DM and CCM groups

\begin{tabular}{lcccccc}
\hline Group & MEP-ADM & PCT-ADM & CMCT-ADM & MEP-AH & PCT-AH & CMCT-AH \\
\hline CCM-DM & & & & & & \\
\hline No. & 22 & 22 & 22 & 22 & 22 & 22 \\
\hline Abnormal case & 14 & 16 & 12 & 18 & 13 & 19 \\
\hline$\%$ & 64 & 73 & 54 & 82 & 59 & 86 \\
\hline p vs CCM & 0.800 & $0.009^{*}$ & 0.815 & $0.029^{*}$ & $0.004^{*}$ & 0.074 \\
\hline CCM & & & & & 92 & 92 \\
\hline No. & 92 & 92 & 92 & 92 & 23 & 61 \\
\hline Abnormal case & 63 & 38 & 53 & 51 & 25 & 66 \\
\hline$\%$ & 68 & 41 & 58 & 55 & &
\end{tabular}


The CMCT correlates with clinical assessment in patients with CCM. Correlations between CMCT and the JOA score have been reported. ${ }^{31,37}$ However, our results showed no correlation between the JOA score and CMCT in the CCM-DM group. In the CCM-DM group, the JOA score correlated with the MEP-AH and PCT-AH before and after surgery, while the JOA score before surgery correlated with the CMCT and MEP values in the CCM group. Pan et al. reported that the measurement of F-waves in the tibial and fibular nerves is the most sensitive method to detect subclinical or overt diabetic polyneuropathy. ${ }^{34}$ The PCT parameters in the tibial nerve were contained in MEP-AH values together with the CMCT, which may result in the correlation observed between the JOA score and MEP-AH values in our diabetic patients.

CMCT is a useful parameter in spinal pathology for predicting the outcome of surgical treatment. ${ }^{37} \mathrm{CMCT}$ values improved after cervical laminoplasty with significant correlations to the JOA score before and after surgery. ${ }^{31}$ Moreover, sufficient clinical results have been reported even in myelopathy patients older than 80 years, provided the patients are selected correctly through electrophysiological evaluation via MEP and CMCT study. ${ }^{38}$ However, those studies excluded diabetic patients or did not clearly mention the patients with DM. In diabetic patients with CCM in our study, the JOA score improved significantly after surgery. Moreover, MEP and PCT values correlated with the JOA score before and after surgery. Together, our results suggest that MEP, PCT, and CMCT studies may be effective in screening patients for CCM who would benefit from surgical intervention, even in diabetic patients. However, the functional variations in the motor pathway after cervical laminoplasty are unclear in the diabetic patients with CCM. Further study is needed to investigate the function after surgery.

The JOA score evaluates motor function in the extremities and bladder function, as well as sensory function in the body and extremities. In our study, the CMCT and PCT parameters were calculated from MEPs, F-wave, and M-wave latencies to evaluate the conductivity of the corticospinal tract and peripheral motor function. F-wave latencies are considered the most sensitive measure of diabetic neuropathy, 1,18 especially for subclinical abnormalities in patients with normal nerve conduction parameters. ${ }^{34}$ Therefore, we examined F-waves in the present study. One limitation to this study is that we did not conduct an electrophysiological investigation of sensory nerve conduction, and the factors that impact the JOA score were not clarified. As another limitation, it is difficult to discriminate the asymptomatic diabetic neuropathy or developed deterioration in the lower motor neuron after the onset of CCM. Symptoms associated with CCM, such as sensory disturbance, numbness, motor weakness in the limbs, or bladder and bowel dysfunction, may mask the symptoms induced by diabetic neuropathy.

\section{Conclusions}

In conclusion, our results suggest that MEP, PCT, and CMCT reveal abnormalities in both the upper and lower motor neurons, even in patients with DM. Our results also show that a prolonged PCT may exist in DM patients with
CCM, even though these patients have no history of diabetic neuropathy. In addition, our results demonstrate that corticospinal tract impairments were similar between the diabetic and nondiabetic patients with CCM, while the JOA score in diabetic patients was lower than that in nondiabetic patients. The JOA score in the CCM-DM patients may be influenced by additional impairments in peripheral nerves or other diabetic complications. These electrophysiological studies may be effective for screening motor pathway function for CCM patients, even those with DM.

\section{Acknowledgment}

Supported by the Grants-in-Aid for Scientific Research (Scientific Research C, Research Project Number: 24592198) from Japan Society for the Promotion of Science, Ministry of Health, Labour and Welfare.

\section{References}

1. Andersen H, Stålberg E, Falck B: F-wave latency, the most sensitive nerve conduction parameter in patients with diabetes mellitus. Muscle Nerve 20:1296-1302, 1997

2. Chistyakov AV, Soustiel JF, Hafner H, Kaplan B, Feinsod M: The value of motor and somatosensory evoked potentials in evaluation of cervical myelopathy in the presence of peripheral neuropathy. Spine (Phila Pa 1976) 29:E239-E247, 2004

3. Chu NS: Motor evoked potentials with magnetic stimulation: correlations with height. Electroencephalogr Clin Neurophysiol 74:481-485, 1989

4. Claus D: Central motor conduction: method and normal results. Muscle Nerve 13:1125-1132, 1990

5. Conrad B, Aschoff JC, Fischler M: [The diagnostic value of the F wave latency (author's transl).] J Neurol 210:151-159, 1975 (Ger)

6. Di Lazzaro V, Restuccia D, Colosimo C, Tonali P: The contribution of magnetic stimulation of the motor cortex to the diagnosis of cervical spondylotic myelopathy. Correlation of central motor conduction to distal and proximal upper limb muscles with clinical and MRI findings. Electroencephalogr Clin Neurophysiol 85:311-320, 1992

7. Dorfman LJ, Bosley TM: Age-related changes in peripheral and central nerve conduction in man. Neurology 29:38-44, 1979

8. Dvorák J, Herdmann J, Theiler R, Grob D: Magnetic stimulation of motor cortex and motor roots for painless evaluation of central and proximal peripheral motor pathways. Normal values and clinical application in disorders of the lumbar spine. Spine (Phila Pa 1976) 16:955-961, 1991

9. Furby A, Bourriez JL, Jacquesson JM, Mounier-Vehier F, Guieu JD: Motor evoked potentials to magnetic stimulation: technical considerations and normative data from 50 subjects. J Neurol 239:152-156, 1992

10. Hasegawa K, Homma T, Chiba Y, Hirano T, Watanabe K, Yamazaki A: Effects of surgical treatment for cervical spondylotic myelopathy in patients $>$ or $=70$ years of age: a retrospective comparative study. J Spinal Disord Tech 15:458-460, 2002

11. Hayashi H, Okada K, Hashimoto J, Tada K, Ueno R: Cervical spondylotic myelopathy in the aged patient. A radiographic evaluation of the aging changes in the cervical spine and etiologic factors of myelopathy. Spine (Phila Pa 1976) 13:618625,1988

12. Jaiser SR, Barnes JD, Baker SN, Baker MR: A multiple regression model of normal central and peripheral motor conduction times. Muscle Nerve 51:706-712, 2014

13. Jaskolski DJ, Jarratt JA, Jakubowski J: Clinical evaluation of magnetic stimulation in cervical spondylosis. Br J Neurosurg 3:541-548, 1989 
14. Kaneko K, Kawai S, Taguchi T, Fuchigami Y, Shiraishi G: Coexisting peripheral nerve and cervical cord compression. Spine (Phila Pa 1976) 22:636-640, 1997

15. Kaneko K, Taguchi T, Morita H, Yonemura H, Fujimoto H, Kawai S: Mechanism of prolonged central motor conduction time in compressive cervical myelopathy. Clin Neurophysiol 112:1035-1040, 2001

16. Kimura J: F-wave velocity in the central segment of the median and ulnar nerves. A study in normal subjects and in patients with Charcot-Marie-Tooth disease. Neurology 24:539-546, 1974

17. Kimura J: Principles and pitfalls of nerve conduction studies. Ann Neurol 16:415-429, 1984

18. Kimura J, Yamada T, Stevland NP: Distal slowing of motor nerve conduction velocity in diabetic polyneuropathy. J Neurol Sci 42:291-302, 1979

19. King D, Ashby P: Conduction velocity in the proximal segments of a motor nerve in the Guillain-Barré syndrome. J Neurol Neurosurg Psychiatry 39:538-544, 1976

20. Kohara N, Kimura J, Kaji R, Goto Y, Ishii J, Takiguchi M, et al: F-wave latency serves as the most reproducible measure in nerve conduction studies of diabetic polyneuropathy: multicentre analysis in healthy subjects and patients with diabetic polyneuropathy. Diabetologia 43:915-921, 2000

21. Kokubun S, Sato T, Ishii Y, Tanaka Y: Cervical myelopathy in the Japanese. Clin Orthop Relat Res (323):129-138, 1996

22. Kuzuya T, Nakagawa S, Satoh J, Kanazawa Y, Iwamoto Y, Kobayashi M, et al: Report of the Committee on the classification and diagnostic criteria of diabetes mellitus. Diabetes Res Clin Pract 55:65-85, 2002

23. Lo YL, Chan LL, Lim W, Tan SB, Tan CT, Chen JLT, et al: Systematic correlation of transcranial magnetic stimulation and magnetic resonance imaging in cervical spondylotic myelopathy. Spine (Phila Pa 1976) 29:1137-1145, 2004

24. Machino M, Yukawa Y, Hida T, Ito K, Nakashima H, Kanbara S, et al: Can elderly patients recover adequately after laminoplasty?: a comparative study of 520 patients with cervical spondylotic myelopathy. Spine (Phila Pa 1976) 37:667-671, 2012

25. Machino M, Yukawa Y, Ito K, Inoue T, Kobayakawa A, Matsumoto T, et al: Impact of diabetes on the outcomes of cervical laminoplasty: a prospective cohort study of more than 500 patients with cervical spondylotic myelopathy. Spine (Phila Pa 1976) 39:220-227, 2014

26. Maertens de Noordhout A, Remacle JM, Pepin JL, Born JD, Delwaide PJ: Magnetic stimulation of the motor cortex in cervical spondylosis. Neurology 41:75-80, 1991

27. Matsuda Y, Shibata T, Oki S, Kawatani Y, Mashima N, Oishi $\mathrm{H}$ : Outcomes of surgical treatment for cervical myelopathy in patients more than 75 years of age. Spine (Phila Pa 1976) 24:529-534, 1999

28. Naderi S, Ozgen S, Pamir MN, Ozek MM, Erzen C: Cervical spondylotic myelopathy: surgical results and factors affecting prognosis. Neurosurgery 43:43-50, 1998

29. Nakanishi K, Tanaka N, Fujiwara Y, Kamei N, Ochi M: Corticospinal tract conduction block results in the prolongation of central motor conduction time in compressive cervical myelopathy. Clin Neurophysiol 117:623-627, 2006

30. Nakanishi K, Tanaka N, Kamei N, Hamasaki T, Nishida K, Touten Y, et al: Significant correlation between corticospinal tract conduction block and prolongation of central motor conduction time in compressive cervical myelopathy. J Neurol Sci 256:71-74, 2007

31. Nakanishi K, Tanaka N, Kamei N, Ohta R, Fujioka Y, Hiramatsu T, et al: Electrophysiological evidence of functional improvement in the corticospinal tract after laminoplasty in patients with cervical compressive myelopathy. Clinical article. J Neurosurg Spine 21:210-216, 2014

32. Nakanishi K, Tanaka N, Sasaki H, Kamei N, Hamasaki T, Yamada K, et al: Assessment of central motor conduction time in the diagnosis of compressive thoracic myelopathy. Spine (Phila Pa 1976) 35:E1593-E1598, 2010

33. Ofuji A, Kaneko K, Taguchi T, Fuchigami Y, Morita H, Kawai S: New method to measure central motor conduction time using transcranial magnetic stimulation and T-response. J Neurol Sci 160:26-32, 1998

34. Pan H, Jian F, Lin J, Chen N, Zhang C, Zhang Z, et al: Fwave latencies in patients with diabetes mellitus. Muscle Nerve 49:804-808, 2014

35. Panayiotopoulos CP, Scarpalezos S, Nastas PE: F-wave studies on the deep peroneal nerve. Part 1. Control subjects. J Neurol Sci 31:319-329, 1977

36. Puksa L, Stålberg E, Falck B: Reference values of F wave parameters in healthy subjects. Clin Neurophysiol 114:10791090, 2003

37. Takahashi J, Hirabayashi H, Hashidate H, Ogihara N, Yamazaki I, Kamimura M, et al: Assessment of cervical myelopathy using transcranial magnetic stimulation and prediction of prognosis after laminoplasty. Spine (Phila Pa 1976) 33:E15-E20, 2008

38. Tanaka N, Nakanishi K, Fujimoto Y, Sasaki H, Kamei N, Hamasaki T, et al: Clinical results of cervical myelopathy in patients older than 80 years of age: evaluation of spinal function with motor evoked potentials. J Neurosurg Spine 11:421-426, 2009

39. Tanaka N, Nakanishi K, Fujimoto Y, Sasaki H, Kamei N, Hamasaki T, et al: Expansive laminoplasty for cervical myelopathy with interconnected porous calcium hydroxyapatite ceramic spacers: comparison with autogenous bone spacers. J Spinal Disord Tech 21:547-552, 2008

40. Tavy DL, Wagner GL, Keunen RW, Wattendorff AR, Hekster RE, Franssen H: Transcranial magnetic stimulation in patients with cervical spondylotic myelopathy: clinical and radiological correlations. Muscle Nerve 17:235-241, 1994

41. Tobimatsu S, Sun SJ, Fukui R, Kato M: Effects of sex, height and age on motor evoked potentials with magnetic stimulation. J Neurol 245:256-261, 1998

42. Yonenobu K, Abumi K, Nagata K, Taketomi E, Ueyama K: Interobserver and intraobserver reliability of the japanese orthopaedic association scoring system for evaluation of cervical compression myelopathy. Spine (Phila Pa 1976) 26:1890-1895, 2001

43. Zappia M, Valentino P, Marchello LP, Paniccia M, Montagna $\mathrm{P}$ : F-wave normative studies in different nerves of healthy subjects. Electroencephalogr Clin Neurophysiol 89:67-72, 1993

\section{Disclosure}

The authors report no conflict of interest concerning the materials or methods used in this study or the findings specified in this paper.

\section{Author Contributions}

Conception and design: Nakanishi, Ochi. Acquisition of data: Nakanishi, Kamei, Hiramatsu, Ujigo, Sumiyoshi, Rikita. Analysis and interpretation of data: Nakanishi. Drafting the article: Nakanishi. Critically revising the article: Tanaka, Kamei, Hiramatsu, Ujigo, Sumiyoshi, Rikita, Takazawa. Reviewed submitted version of manuscript: Tanaka, Kamei, Hiramatsu, Ujigo, Sumiyoshi, Rikita, Takazawa, Ochi. Approved the final version of the manuscript on behalf of all authors: Nakanishi. Statistical analysis: Nakanishi. Study supervision: Ochi.

\section{Correspondence}

Kazuyoshi Nakanishi, Department of Orthopedic Surgery, Integrated Health Sciences, Institute of Biomedical \& Health Sciences, Hiroshima University, 1-2-3 Kasumi, Minami-ku, Hiroshima 734-8551, Japan.email: kazn@hiroshima-u.ac.jp. 